\title{
Spectrophotometric Screening for Potential Inhibitors of Cytosolic Glutathione S-Transferases
}

\author{
Shannon K. D. Robin ${ }^{1,2}$, Marc Ansari ${ }^{*}, 1,3$, Chakradhara Rao S. Uppugunduri ${ }^{*}, 1,3$ \\ ${ }^{1}$ Research platform of Pediatric Onco-Hematology, Department of Paediatrics, Gynaecology and Obstetrics, Faculty of Medicine, University of \\ Geneva ${ }^{2}$ Section of Biology, Faculty of Science, University of Geneva ${ }^{3}$ Onco-Hematology Unit, Department of Women, Children-Adolescents, University \\ Hospitals of Geneva \\ *These authors contributed equally
}

\section{Corresponding Authors}

Marc Ansari

Marc.Ansari@hcuge.ch

Chakradhara Rao S. Uppugunduri

Chakradhara.Uppugunduri@unige.ch

\section{Citation}

Robin, S.K.D., Ansari, M., Uppugunduri, C.R.S. Spectrophotometric Screening for Potential Inhibitors of Cytosolic Glutathione STransferases. J. Vis. Exp. (164), e61347, doi:10.3791/61347 (2020).

\section{Date Published}

October 10, 2020

DOI

$10.3791 / 61347$

URL

jove.com/video/61347

\section{Abstract}

Glutathione S-transferases (GSTs) are metabolic enzymes responsible for the elimination of endogenous or exogenous electrophilic compounds by glutathione (GSH) conjugation. In addition, GSTs are regulators of mitogen-activated protein kinases (MAPKs) involved in apoptotic pathways. Overexpression of GSTs is correlated with decreased therapeutic efficacy among patients undergoing chemotherapy with electrophilic alkylating agents. Using GST inhibitors may be a potential solution to reverse this tendency and augment treatment potency. Achieving this goal requires the discovery of such compounds, with an accurate, quick, and easy enzyme assay. A spectrophotometric protocol using 1-chloro-2,4-dinitrobenzene (CDNB) as the substrate is the most employed method in the literature. However, already described GST inhibition experiments do not provide a protocol detailing each stage of an optimal inhibition assay, such as the measurement of the Michaelis-Menten constant $\left(\mathrm{K}_{\mathrm{m}}\right)$ for CDNB or indication of the employed enzyme concentration, crucial parameters to assess the inhibition potency of a tested compound. Hence, with this protocol, we describe each step of an optimized spectrophotometric GST enzyme assay, to screen libraries of potential inhibitors. We explain the calculation of both the half-maximal inhibitory concentration (IC50) and the constant of inhibition $\left(\mathrm{K}_{\mathrm{i}}\right)$ two characteristics used to measure the potency of an enzyme inhibitor. The method described can be implemented using a pool of GSTs extracted from cells or pure recombinant human GSTs, namely GST alpha 1 (GSTA1), GST mu 1 (GSTM1) or GST pi 1 (GSTP1). However, this protocol cannot be applied to GST theta 1 (GSTT1), as CDNB is not a substrate for this isoform. This method was used to test the inhibition potency of curcumin using GSTs from equine liver. Curcumin is a molecule exhibiting anti-cancer properties and showed affinity towards GST isoforms after in silico docking predictions. We demonstrated that curcumin is a potent competitive GST inhibitor, with 
an IC50 of $31.6 \pm 3.6 \mu \mathrm{M}$ and a $\mathrm{K}_{\mathrm{i}}$ of $23.2 \pm 3.2 \mu \mathrm{M}$. Curcumin has potential to be combined with electrophilic chemotherapy medication to improve its efficacy.

\section{Introduction}

Cytosolic glutathione S-transferase enzymes (GSTs, EC 2.5.1.18) catalyze the conjugation of glutathione (GSH) into various electrophilic compounds, such as chemotherapeutic agents, to detoxify and eliminate them easily from the body ${ }^{1}$. Seven isoforms of cytosolic GST have been identified as alpha, mu, pi, sigma, omega, theta, and zeta. GSTs are mainly expressed in the liver, testes, lungs, and gastrointestinal tract ${ }^{2}$. The GST alpha 1 (GSTA1) isoform is highly expressed in hepatocytes. The body heterogeneously expresses other subtypes, including GST pi 1 (GSTP1) predominantly in the brain, heart, and lungs, and GST mu 1 (GSTM1) in the liver and testes ${ }^{3}$. Although there is high sequence homology between GST isoforms, each exhibits substrate specificity and is implicated in drug metabolism and cancer in different ways, according to its differential expression $^{4,5}$.

Electrophilic compounds either enter the body exogenously or are produced endogenously. Pesticides, prostaglandins, carcinogens, and chemotherapeutic drugs are some of the potential substrates for glutathione conjugation reactions ${ }^{6}$. For example, any electron-deficient reactive compound formed within a cell is likely to become an electrophilic substrate. Alkylating agents such as chlorambucil or melphalan are eliminated as conjugates of GSH catalyzed by GSTs, and increased levels of these enzymes have been correlated with resistance to these compounds ${ }^{6,7}$.

Another important role of cytosolic GSTs is regulating the activity of mitogen-activated protein kinases (MAPK) such as MAPK8 (also known as c-Jun N-terminal kinase, or JNK1) and MAP3K5 (also known as apoptosis signal-regulating kinase 1 , or $A S K 1)^{8}$. Some isoforms in their monomeric conformation will bind to these proteins and thus block the phosphorylation cascade. Under normal conditions, the GSTP1 isoform will sequester MAPK8 (the activator of the C-Jun protein). Combining the C-Jun with the c-Fos protein forms the activator protein 1 (AP-1) transcription factor, which is responsible for transcribing pro-apoptotic genes. In stressed cells, the complex formed by GSTP1 and MAPK8 dissociates, c-Jun is activated, and the genes leading to apoptosis start to be expressed ${ }^{9}$. Greater expression of this GST isoform might therefore block the pathway, leading to increased cell viability, more cellular proliferation, and lower cellular sensitivity to chemotherapy. Similar scenarios may occur with paralogs of GSTP1, for example, GSTM1, which interacts with MAP $3 \mathrm{~K} 5^{10}$.

The roles played by GSTs in drug metabolism and in the sequestration of MAPKs led to the hypothesis that a greater expression of GSTs might be a sign of a tumoral resistance mechanism to chemotherapeutic treatment ${ }^{6,11}$. For example, GSTP1 is overexpressed in numerous cancers and its presence has been correlated with a poor prognosis and an increased incidence of relapse ${ }^{8}$. Polymorphism in these genes has also shown differential drug exposure and survival rates for patients presenting various diseases, reinforcing the idea that these enzymes are crucial to mechanisms of drug resistance. For instance, individuals with the GSTM1 null genotype are associated with lower drug clearance and better survival ${ }^{12,13}$. There are several 
potential means of countering this overexpression, such as the use of GSH analogues, prodrugs that are activated by conjugation with GSTs, or direct GST inhibitors ${ }^{14,15}$.

All these methods are currently under investigation, and a few compounds have begun clinical trials for their potential usage among patients. However, to the best of our knowledge, there are no compounds in use as GST inhibitors in clinical settings ${ }^{15}$. Indeed, a lack of specificity for certain isoforms or the depletion of GSH in normal cells, which may lead to toxicities caused by the accumulation of reactive oxygen species (ROS) in organ systems, are just some of the drawbacks which reduce the potential of GST inhibitors ${ }^{14,15}$. The risk that these compounds might exert other pharmacodynamic effects on the body are also limiting their usage. Ethacrynic acid, for instance, is the most widely studied GST inhibitor in laboratory environments, but because it is primarily used as a strong diuretic, this property limits its use in combination with other drugs in clinical settings. Curcumin is another natural compound successfully screened as a GST inhibitor. This molecule is a polyphenol ether extracted from the Curcuma longa species of turmeric. It has shown promising results as a possible treatment option against cancer by inducing the apoptosis of various kind of tumor cell lines ${ }^{16,17}$. The compound can regulate diverse cellular pathways, such as the tyrosine kinase ${ }^{18}$ or the GST pathway. Studies with pure proteins have shown its inhibition potency on GSTA1, GSTM1 and GSTP1 ${ }^{19,20}$. However, conflicting results were observed in cancer cells, where greater intracellular GST activity was measured when cells were treated with curcumin ${ }^{21}$. Thus, it is important to investigate half-maximal inhibitory concentration (IC50) and the constant of inhibition $\left(\mathrm{K}_{\mathrm{i}}\right)$ of any putative GST inhibitor using a clearly described protocol with proper controls before planning any further cellular experiments.

Screening and testing potential new GST inhibitors is therefore of significant clinical interest, and any new compound found must be safe and efficient for use in combination with electrophilic drugs. Focusing research on isoform-specific inhibitors might enable GST inhibition in tumor tissues exhibiting specific patterns of GST expression, thus allowing the development of an effective combination therapy. Finding inhibitors with differential modes of inhibition might also be of interest. For instance, a competitive inhibitor that uses GSH as a substrate can induce its depletion. This reduction of the GSH concentration in cells was shown to induce oxidative stress in neurons, leading to apoptosis. Another common mode of inhibition-uncompetitive inhibition —cannot be reversed even if the substrate is present in high concentrations.

The rate of enzymatic activity is represented by the MichaelisMenten constant $\left(\mathrm{K}_{\mathrm{m}}\right)$ and the maximum velocity $\left(\mathrm{V}_{\max }\right)$, which can be determined by plotting a Michaelis-Menten graph, with the substrate concentration against the velocity of the reaction ${ }^{23} . \mathrm{K}_{\mathrm{m}}$ is the concentration of substrate required to occupy half the enzymatic active sites, meaning that a high $\mathrm{K}_{\mathrm{m}}$ represent less affinity. $\mathrm{V}_{\max }$ represents the maximum velocity of the reaction, reached when all the active sites are occupied by the substrate. $\mathrm{K}_{\mathrm{m}}$ is equal to half $V_{\max }$. There are three most common modes of inhibition: competitive, uncompetitive, and noncompetitive. In case of competitive inhibition, the inhibitor binds to the active site of the enzyme and competes with the substrate. Hence, $V_{\text {max }}$ does not change after addition of the inhibitor, but $\mathrm{K}_{\mathrm{m}}$ increases, as more substrate is needed to counter the inhibition. Uncompetitive inhibition occurs only when the 
substrate forms a complex with the enzyme. In this case, as the level of inhibition depends on the substrate and enzyme concentration, $\mathrm{V}_{\max }$ and $\mathrm{K}_{\mathrm{m}}$ decrease when the inhibitor is added to the reaction. The last mode of inhibition is noncompetitive and is a mix of the two other inhibition patterns. The inhibitor can bind to the active site of the enzyme whether the enzyme is bound to its substrate or not. Here $V_{\max }$ decreases after addition of the inhibitor, but $\mathrm{K}_{\mathrm{m}}$ does not change $^{24}$.

A spectrophotometric assay that measured the GST activity was first developed by Habig et al. in 1974 using 1chloro-2,4-dinitrobenzene (CDNB) as the substrate for the reaction $^{22}$. Conjugation between GSH and CDNB forms GSDNB, which exhibits a maximum light absorbance at the wavelength of $340 \mathrm{~nm}$, recordable with a spectrophotometer. Most of the technique explained below is derived from Habig et al., including information on the best settings and important optimization points for an inhibitory assay. The technique can be applied to screening potential GST inhibitors, whether chosen by rational drug selection using computational predictions or by literature review. How to adapt the protocol to newly synthesized GST proteins or specific isoforms is also discussed. For instance, testing the inhibitory potency of GST isoforms exhibiting a clinically relevant polymorphism or of single-nucleotide polymorphisms (SNPs) could be potential uses for this protocol, targeting patient-specific GSTs.

This protocol provides a quick, feasible, and effective method for the screening of potential GST inhibitors in vitro before any other functional studies. The steps needed to evaluate the most commonly measured characteristics of an enzymatic inhibitor are described: the inhibitory concentration 50 (IC50) that is concentration of inhibitor required to decrease the enzymatic activity by half; and the constant of inhibition $\left(\mathrm{K}_{\mathrm{i}}\right)$ that represents the equilibrium constant of the dissociation between the inhibitor and the enzyme, characteristic of the affinity between these two molecules. These two values are measured by non-linear regression and using equations specific for each mode of inhibition, respectively. We also demonstrate the assessment of this pattern of inhibition, using Michaelis-Menten plots to determine the change of $\mathrm{V}_{\max }$ and $\mathrm{K}_{\mathrm{m}}$ after addition of the inhibitor $23,25,26$.

\section{Protocol}

\section{Preparation of the GST enzyme solution}

NOTE: The procedure for preparing the enzyme solution depends upon whether or not the units of enzymatic activity are known before the assay. One enzymatic unit is the amount of enzyme needed to synthesize $1 \mu \mathrm{mol}$ of product per minute. Enzymatic activity is represented in unit/mL or $\mu \mathrm{mol} / \mathrm{min} / \mathrm{mL}$ and depends on the dilution of the enzymatic solution. Specific enzymatic activity is represented in unit/ $\mathrm{mg}$ or $\mu \mathrm{mol} / \mathrm{min} / \mathrm{mg}$ and depends solely on the purity of the solution. Both these characteristics are determined below. If the enzymatic unit of an isolated GST isoform is unknown, it must be estimated to adjust the enzymatic concentrations for each reaction and provide reproducible results.

1. If the enzymatic unit of the GST used in the assay is known:

1. Prepare a fresh stock solution of the GST enzyme at $0.1 \mathrm{U} / \mathrm{mL}$ in water and then proceed with step 2.

NOTE: This solution can be stored at $-20{ }^{\circ} \mathrm{C}$ in aliquots for several months or at $-80{ }^{\circ} \mathrm{C}$ for longer periods, but the freeze/thaw cycle must be avoided. 
2. If the enzymatic unit of the GST used in the assay is unknown:

1. Quantify the enzyme solution's protein concentration using a bicinchoninic acid (BCA) protein assay, or any other kit.

2. Dilute the protein solution to a final protein concentration of $0.02 \mathrm{mg} / \mathrm{mL}$.

3. Add $20 \mu \mathrm{L}$ of the enzyme solution, $20 \mu \mathrm{L}$ of $\mathrm{GSH}$ $25 \mathrm{mM}$ (molecular weight: $307.32 \mathrm{~g} / \mathrm{mol}$ ), and $150 \mu \mathrm{L}$ of Dulbecco's phosphate-buffered saline (DPBS) to a 96-well plate. For the blank, add $20 \mu \mathrm{L}$ of water instead of the enzyme solution.

4. Add $10 \mu \mathrm{L}$ of CDNB $50 \mathrm{mM}$ (molecular weight: 202.55 $\mathrm{g} / \mathrm{mol}$ ) substrate to each well.

5. On a spectrophotometric microplate reader, set the parameters for reading the wells at $340 \mathrm{~nm}$. It is recommended to measure the absorbance every minute for 10 minutes.

6. Insert the plate into the microplate reader, and start the reading according to settings of step 1.2.5.

7. Calculate the change in absorbance per minute for the enzymatic samples and the blank.

NOTE: Verify that the reaction is linear by plotting absorbance on $y$-axis and minutes on the $x$-axis. If the reaction is not linear and reaches a plateau, it means that all the substrate is used and the reaction is too quick. Thus, reduce the amount of enzyme added to the well by diluting the stock solution by two.

8. Blank-correct the test samples' absorbance readings.

9. With equation 1, representing the Beer-Lambert law, calculate the concentration of GS-DNB formed (in $\mu \mathrm{M}$ ) by the reaction each minute.

\section{Equation 1:}

$C=\frac{A 340 / \min }{\varepsilon * l}$

where $\mathrm{C}$ is the concentration of the substrate in $\mu \mathrm{M}$, A340/min is the change in absorbance per minute, as measured in step 1.2.7, $\varepsilon$ is the molar extinction coefficient for the CDNB conjugate at $340 \mathrm{~nm}(0.0096$ $\left.\mu \mathrm{M}^{-1 *} \mathrm{~cm}^{-1}\right)$, and $\mathrm{I}$ is the length of the light path in the well (in cm). For a 96-well plate filled with $200 \mu \mathrm{L}$ of enzymatic solution, the path length is around $0.55 \mathrm{~cm}$. This value can vary according to the plate model and should be verified with the manufacturer.

10. To determine the amount of product present in one well in $\mu \mathrm{mol} / \mathrm{min}$, multiply the results found using equation 1 by the volume of solution, $2 \times 10^{-4} \mathrm{~L}$.

11. Normalize the activity per amount of protein used by dividing the results of step 1.2 .9 by $4 \times 10^{-4} \mathrm{mg}$. The result is the specific enzymatic activity in unit/mg or $\mu \mathrm{mol} / \mathrm{min} / \mathrm{mg}$.

NOTE: If the dilution was changed in step 1.2.6, because of a non-linear reaction, adjust the protein amount accordingly.

12. To find the enzymatic activity, adjust the results to the protein concentration in $\mathrm{mg} / \mathrm{mL}$ by multiplying the specific enzymatic activity found in step 1.2 .10 by $0.002 \mathrm{mg} / \mathrm{mL}$. This will give the enzymatic activity in unit $/ \mathrm{mL}$ or $\mu \mathrm{mol} / \mathrm{min} / \mathrm{mL}$.

NOTE: In contrast to the enzymatic activity, this measure will not change depending on the dilution of the protein solution. Same note as step 1.2.10 but for the protein concentration.

13. Prepare a stock solution of the GST enzyme at 0.1 unit $/ \mathrm{mL}$ in water and then proceed with step 2. 
NOTE: This solution can be stored at $-20{ }^{\circ} \mathrm{C}$ in aliquots for several months or at $-80{ }^{\circ} \mathrm{C}$ for longer periods, but the freeze/thaw cycle must be avoided. Control of the enzymatic activity is recommended if the experiments are conducted during an extended period of time as degradation of the protein solution might occur.

\section{Measurement of the Michaelis-Menten constant of the GST isoform for CDNB}

NOTE: The procedure is explained for a CDNB substrate but can be applied to any other substrate, such as GSH. Each concentration of CDNB needs its own blank, as the absorbance at $340 \mathrm{~nm}$ will increase according to the CDNB concentration.

1. Prepare six different concentrations of CDNB, ranging from $10 \mathrm{mM}$ to $100 \mathrm{mM}$, in ethanol $95 \%(\mathrm{v} / \mathrm{v})$.

2. Prepare the assay solution, with $10 \mu \mathrm{L}$ of CDNB, $20 \mu \mathrm{L}$ of GST enzyme, $20 \mu \mathrm{L}$ of GSH $25 \mathrm{mM}$, and $150 \mu \mathrm{L}$ DPBS. For the blank, instead of the CDNB solution, add only 10 $\mu \mathrm{L}$ of ethanol $95 \%$.

3. Prepare a blank for each CDNB concentration, with $10 \mu \mathrm{L}$ of CDNB, $20 \mu \mathrm{L}$ of water, $20 \mu \mathrm{L}$ of GSH $25 \mathrm{mM}$, and 150 $\mu \mathrm{L}$ DPBS.

4. Record the absorbance at $340 \mathrm{~nm}$ every minute for 10 minutes with a microplate reader.

5. Blank-correct the absorbance by subtracting the results from the blank from that of the correct other test wells. According to the measured values, calculate the velocity of the reaction using Equation 2.

\section{Equation 2:}

velocity $\left(\frac{\mu m o l}{m L} / \min\right.$ or $\left.m M / \min \right)=\frac{\frac{A 340}{\min } * V_{\text {total }}}{\varepsilon_{G S-D N B} * V_{\text {enzyme }}}$ where A340/min is the experimentally determined change in absorbance per minute, $V_{\text {total }}$ (total volume) equals 0.2

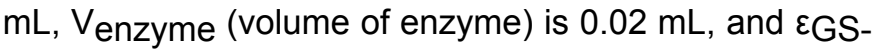
DNB is the molar extinction coefficient of the GS-DNB conjugate at $340 \mathrm{~nm}\left(9.6 \mathrm{mM}^{-1 *} \mathrm{~cm}^{-1}\right)$. In a $200 \mu \mathrm{L}$ well of a 96-well plate, the path length is $0.55 \mathrm{~cm}$ (depending on the plate type) and the extinction coefficient equals 5.3 $\mathrm{mM}^{-1}$. The velocity can be represented either by $\mu \mathrm{mol} /$ $\mathrm{mL} / \mathrm{min}$ or $\mathrm{mM} / \mathrm{min}$.

6. Plot the Michaelis-Menten graph with the velocity (on the $y$-axis) against the substrate concentration (on the $x$-axis).

7. Define the maximum velocity $\left(V_{\max }\right)$ of the reaction and the Michaelis-Menten constant $\left(\mathrm{K}_{\mathrm{m}}\right)$ (i.e., the substrate concentration at half of $V_{\max }$ ).

NOTE: Using software such as GraphPad Prism, the enzyme kinetics curve can be fitted using a non-linear regression for the calculation of the Michaelis-Menten enzyme kinetics parameters, such as $V_{\max }$ and $\mathrm{K}_{\mathrm{m}}$.

8. Prepare a CDNB stock solution at 20 times the calculated $\mathrm{K}_{\mathrm{m}}$ in ethanol $95 \%(\mathrm{v} / \mathrm{v})$.

\section{Absorbance of the potential GST inhibitor}

NOTE: This step is performed to investigate whether the potential GST inhibitor used in the reaction produces a metabolite that increases absorbance at the wavelength being measured. If it does, the amount of inhibitor used will have an impact on the results and a specific blank should be prepared for each concentration.

1. Dilute the inhibitor to the required concentrations.

NOTE: Prepare three different dilutions, preferably the lowest, middle, and highest concentrations tested during the inhibition assay. The maximum DMSO concentration 
in the well should be equal to or less than $1 \%(\mathrm{v} / \mathrm{v})$. We tested the DMSO concentration's effect on the assay in our laboratory, and $1 \%$ did not significantly change GST activity.

2. In a 96-well plate, add $2 \mu \mathrm{L}$ of the potential GST inhibitor, $20 \mu \mathrm{L}$ of $\mathrm{GSH} 25 \mathrm{mM}$, and $168 \mu \mathrm{L}$ of DPBS. Use an appropriate control, with no inhibitor, by adding equal volumes of the solvent used for the inhibitor samples.

3. Incubate the reaction for 10 minutes, to begin the enzymatic reaction.

NOTE: This step can be optimized, by testing different incubation times, with the twin aims of beginning the reaction while avoiding total depletion of the substrate.

4. Add $10 \mu \mathrm{L}$ of CDNB to each well to achieve a final concentration at the $\mathrm{K}_{\mathrm{m}}$ found in step 2 .

5. Shake the plate for few seconds.

6. Record the absorbance at $340 \mathrm{~nm}$ every minute for 10 minutes with a microplate reader.

7. Calculate the change in absorbance per minute.

8. Verify the change in absorbance compared to both the blank reaction and the negative control reaction with no inhibitor.

1. If there is a significant change, use blank for each inhibitor concentration in order to adjust the results.

NOTE: This result indicates that the reaction's constituents, with no GST enzyme, react spontaneously and produce a metabolite that increases absorbance at $340 \mathrm{~nm}$. To correct for this additional absorbance, a specific blank should be measured for each concentration.
2. If there is no significant change in absorbance, use a general blank, containing only the solvent used for the GST inhibitor dilution, for all the concentrations.

\section{Inhibition assay of GST and IC50 assessment}

1. Prepare nine concentrations of the potential GST inhibitor.

NOTE: The concentrations can be adapted according to the results. The aim is to define the bottom and top plateaus of the non-linear regression curve. See the discussion section for more details about this step.

2. Prepare the assay solution by diluting $20 \mu \mathrm{L}$ of the $\mathrm{GSH}$ solution at $25 \mathrm{mM}$ with $148 \mu \mathrm{L}$ of DPBS. Adapt the volume according to the number of wells used in the assay.

3. In a clear 96-well plate, prepare the enzymatic reaction in a final volume of $190 \mu \mathrm{L}$. It is recommended to use a multichannel pipette for these steps.

1. For the test wells, add $20 \mu \mathrm{L}$ of the enzyme solution, 2 $\mu \mathrm{L}$ of the potential GST inhibitor solution and $168 \mu \mathrm{L}$ of the assay solution.

2. For the control, add $20 \mu \mathrm{L}$ of the enzyme solution, 2 $\mu \mathrm{L}$ of the diluent used for the GST inhibitor and 168 $\mu \mathrm{L}$ of the assay solution.

3. For the blank wells, add $20 \mu \mathrm{L}$ of water, $2 \mu \mathrm{L}$ of the potential GST inhibitor and $168 \mu \mathrm{L}$ of the assay solution.

NOTE: If the GST inhibitor absorbs the $340 \mathrm{~nm}$ wavelength, then a specific blank should be prepared for each concentration tested.

4. Add $10 \mu \mathrm{L}$ of the CDNB solution at $20 \mathrm{x} \mathrm{K}_{\mathrm{m}}$ to each well, including the blank. It is recommended to use a multichannel pipette for this step. 
5. Shake the plate for few seconds.

6. Measure the absorbance at $340 \mathrm{~nm}$ every minute for 10 minutes using a microplate reader.

7. Blank-correct the absorbance by subtracting the results from the test well blanks.

8. Normalize the results by dividing the values obtained using the GST inhibitor solution by the control's absorbance per minute with no inhibitor.

9. Plot the non-linear regression graphs of the logarithmic concentration (x-axis) of the inhibitor against the GST activity (y-axis), and thus determine the IC50.

NOTE: GraphPad Prism calculates the IC50 from the nonlinear regression plots by predicting the concentration that will show $50 \%$ of the enzymatic activity in the control. The prediction is based on the bottom and top plateaus, as well as the curve of the slope formed by the sigmoid graph.

\section{Assessment of the $\mathrm{K}$ jand the type of inhibition}

1. Prepare four different CDNB concentrations: three higher and one equal to the $\mathrm{K}_{\mathrm{m}}$ previously found.

2. Prepare three different GST inhibitor concentrations, equal to or below the previously found IC50.

3. Perform the inhibition assay as described in steps 4.2 to 4.7.

4. Calculate the velocity of the reactions using Equation 2.

5. Plot the Michaelis-Menten graphs for each inhibitor concentration and calculate the $V_{\max }$ and $\mathrm{K}_{\mathrm{m}}$ of each reaction
6. According to the changes in $V_{\max }$ and $\mathrm{K}_{\mathrm{m}}$ when using different concentrations, assess the GST inhibitor's mode of inhibition.

NOTE: This step is explained in more detail in the results and discussion sections.

7. Based on the mode of inhibition, calculate the $\mathrm{K}_{\mathbf{i}}$.

NOTE: In GraphPad Prism, different equations will be used to calculate the $\mathrm{K}_{\mathrm{i}}$ according to the nature of the inhibition. The equations used are based on the observed $\mathrm{K}_{\mathrm{m}}$ and $\mathrm{V}_{\mathrm{max}}$ after addition of the inhibitor and compared to the control's $\mathrm{K}_{\mathrm{m}}$ and $\mathrm{V}_{\max }$.

\section{Representative Results}

Michaelis-Menten constant $\left(\mathrm{K}_{\mathrm{m}}\right)$ of CDNB with GST from equine liver

Curcumin is a safe natural compound even after ingestion at higher doses ${ }^{27}$ that showed anticancer properties ${ }^{16}$. The inhibitory potency of this molecule has been demonstrated on human recombinant GSTs ${ }^{19,20}$. By using the described protocol, we evaluated curcumin's effect on GST activity using a pool of GST isoforms from equine liver. According to the supplier, the specific activity of this mix of proteins is $25 \mathrm{U} /$ mg. A stock solution of $0.1 \mathrm{U} / \mathrm{mL}$ was prepared by dissolving the lyophilized powder in the appropriate amount of water. Ethacrynic acid was used in parallel as a positive control as this compound is the most widely used GST inhibitor in studies. Steps in setting up a GST activity assay and testing of inhibitors is outlined in Figure 1.

The $K_{m}$ has to be defined for each enzyme substrate reaction because using the substrate concentration equivalent to $\mathrm{K}_{\mathrm{m}}$ would ensure no bias regarding the determination of the mode of inhibition ${ }^{28}$. Six different concentrations of CDNB, ranging 
from $0.5 \mathrm{mM}$ to $5 \mathrm{mM}$, were tested to measure this parameter, using a fixed concentration of $2.5 \mathrm{mM} \mathrm{GSH}$.

The reaction's final volume was $200 \mu \mathrm{L}$, in a 96-well plate. A specific blank was used for each experiment, using the same concentration of CDNB as the test well because spontaneous conjugation of CDNB and GSH could occur and might increase absorbance. A final enzyme concentration of $0.01 \mathrm{unit} / \mathrm{mL}$ was used for all the reactions, by adding $20 \mu \mathrm{L}$ of the stock solution to the assay mix. Absorbance at 340 $\mathrm{nm}$ was recorded every minute for 10 minutes. The velocity (in $\mathrm{mM} / \mathrm{min}$ ) of the reaction was calculated using Equation 2. A Michaelis-Menten graph was plotted of the substrate concentration $(\mathrm{mM})$ against the velocity $(\mu \mathrm{M} / \mathrm{min})$ (Figure 2), and the $\mathrm{K}_{\mathrm{m}}$ of the reaction was calculated. The experiment was repeated until at least three sets of data showed similar results. The $\mathrm{K}_{\mathrm{m}}$ of CDNB with GST from equine liver was measured as $0.26 \pm 0.08 \mathrm{mM}$. A concentration of $0.2 \mathrm{mM}$ of CDNB was used for each inhibitory assay using this batch of GSTs.

No spontaneous formation of a metabolite that absorbed at $340 \mathrm{~nm}$ was measured during experiments using curcumin incubated alone with GSH and CDNB. The same blank was used for every inhibitor concentration in each experiment.

\section{Curcumin's inhibitory potency on GSTs}

Curcumin's inhibitory potency was predicted using an in silico docking simulation with software (e.g., AutoDock Vina version 1.1.2). ${ }^{29}$ The free binding energy between different GST isoforms (namely GSTA1, GSTM1 and GSTP1) and curcumin was predicted (data not shown). Then, the constant of inhibition $\mathrm{K}_{i}$ was calculated using Equation 3.

\section{Equation 3:}

$K i(u M)=\exp \left(\frac{\Delta G}{R * T}\right)$

where $\Delta \mathrm{G}$ is the free binding energy found using the in silico analysis, $\mathrm{R}$ is the gas constant of $1.987 \mathrm{cal}^{*} \mathrm{~K}^{-1}{ }^{*} \mathrm{~mol}^{-1}$, and $\mathrm{T}$ is the temperature during the experiment, in this case in Kelvin (298 K).

Based on the free binding energy results returned by the AutoDock Vina, curcumin is a potent GST inhibitor of human GSTA1, GSTM1 and GSTP1, with $\mathrm{K}_{i}$ values of $78.1 \mu \mathrm{M}, 78.1$ $\mu \mathrm{M}$ and $27.4 \mu \mathrm{M}$ respectively. The first inhibitory assays were conducted using these computational $\mathrm{K}_{\mathrm{i}}$ estimations, and the concentrations were adjusted according to the results, if necessary.

First, the IC50 was estimated. This characteristic is the concentration of inhibitor that reduces an enzyme's reaction rate by $50 \%$. It is therefore dependent on the enzyme concentration $^{30}$. Nine final concentrations of the inhibitor were prepared, ranging from $0.39 \mu \mathrm{M}$ to $100 \mu \mathrm{M}$ with each concentration double that of the previous one. The assay solution was composed of $20 \mu \mathrm{L}$ of GSH $2.5 \mathrm{mM}, 20 \mu \mathrm{L}$ of GST from equine liver at $0.01 \mathrm{U} / \mathrm{mL}$ final, $2 \mu \mathrm{L}$ of the curcumin solution, and $148 \mu \mathrm{L}$ of PBS. The control was composed of the same solution with the diluent used for curcumin. This mixture was incubated for 15 minutes to begin the enzyme assay and to avoid degradation of the curcumin in the assay solution, as this compound is unstable in buffer solutions ${ }^{31}$. Next, $10 \mu \mathrm{L}$ of CDNB solution at $4 \mathrm{mM}$ was added to each well, for a final concentration of $0.2 \mathrm{mM}$ CDNB. Absorbance at $340 \mathrm{~nm}$ was recorded every minute for 10 minutes, to calculate changes in absorbance per minute. To calculate the IC50, each sample incubated with curcumin was normalized to the control, to give the percentage of activity. These results were analyzed using the plotting software by calculating the non-linear regression 
of the logarithmic concentration of the inhibitor versus the inhibition. The IC50 found for curcumin on GST from equine liver was $31.6 \pm 3.6 \mu \mathrm{M}$ (Figure $3 \mathrm{~A})$.

The same experiment was conducted in parallel using ethacrynic acid as a positive control, with concentrations ranging from 0.39 to $100 \mu \mathrm{M}$, as with curcumin. The IC50 was found to be $6.6 \pm 1.1 \mu \mathrm{M}$ (Figure 3B).
The next step was to assess curcumin's mode of inhibition on these transferases. Four different concentrations of curcumin were tested: $0,7.5,15$, and $30 \mu \mathrm{M}$, along with four different concentrations of CDNB: $0.2,0.4,1$, and $1.5 \mathrm{mM}$. The protocol was the same as for the previous experiment. Each condition's velocity was calculated using Equation 2. A curve was plotted for each inhibitor concentration, with the velocity (in $\mu \mathrm{M} / \mathrm{min}$ ) against the substrate concentration (mM) (Figure 3C). The $V_{\max }$ and $K_{m}$ were determined based on each plot with GraphPad Prism. The potential inhibitor's mode of inhibition was assessed according to the changes in these two parameters and the assays' different condition. ${ }^{24}$ As $V_{\max }$ did not significantly change between conditions but $\mathrm{K}_{\mathrm{m}}$ increased with the different inhibitor concentrations, curcumin's inhibition of GSTs is competitive. This pattern of inhibition occurs when the inhibitor competes with the substrate for the active site of the enzyme. To measure the $\mathrm{K}_{\mathrm{i}}$ of a competitive inhibitor, GraphPad uses Equation 4 and Equation 5 as described by Copeland et al. $^{32}$.

\section{Equation 4:}

$K m_{o b s}=K m *\left(\frac{1+[I]}{K i}\right)$

\section{Equation 5:}

$Y=V \max * X\left(K m_{o b s}+X\right)$

where $\mathrm{K}_{\mathrm{m}}$ obs is the observed Michaelis-Menten constant, $\mathrm{K}_{\mathrm{m}}$ is the Michaelis-Menten constant of the control, [ $]$ is the inhibitor concentration, $\mathrm{K}_{\mathrm{i}}$ is the constant of inhibition, $\mathrm{Y}$ is the velocity, and $X$ is the substrate concentration.

The calculations are based on the same experiments as the assessment of the mode of inhibition. The $\mathrm{K}_{\mathrm{i}}$ estimated for curcumin's inhibition of GST from equine liver was $23.2 \pm 3.2$ $\mu \mathrm{M}$. 


\section{Preparation of the GST assay}

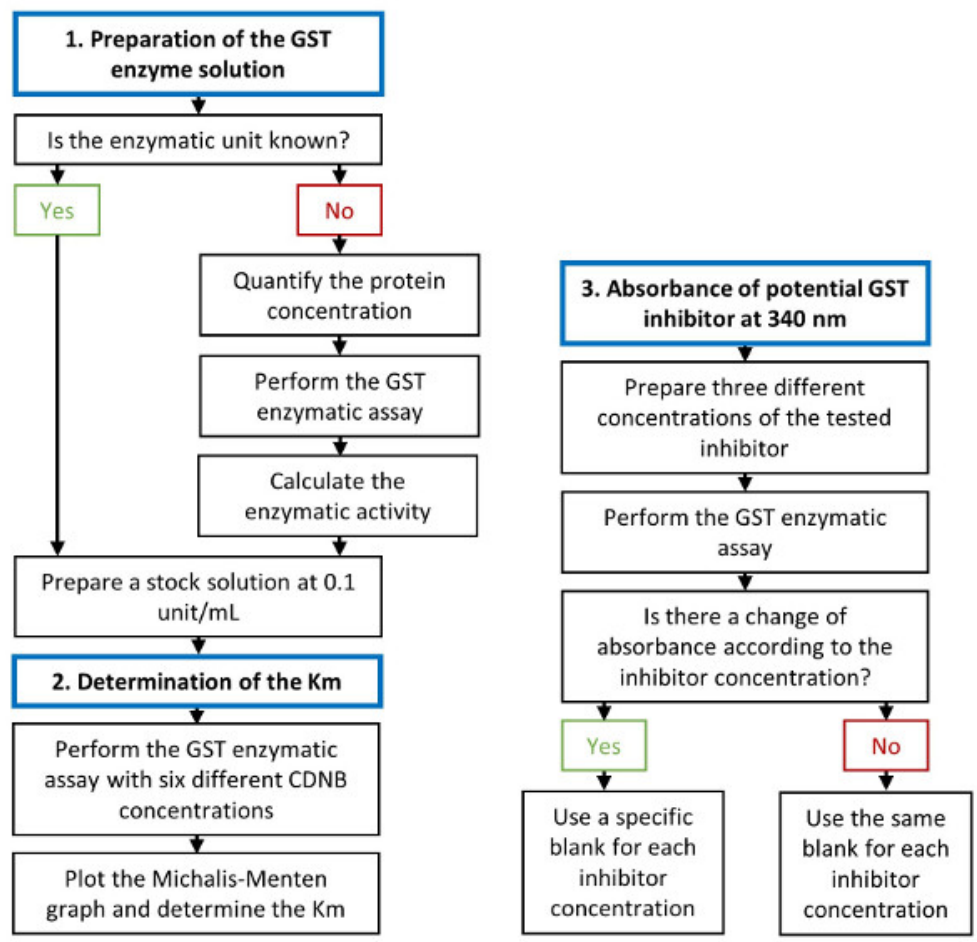

GST inhibition assays

\begin{tabular}{|c|}
\hline 4. IC50 measurement \\
\hline $\begin{array}{c}\text { Perform the GST enzymatic } \\
\text { assay with nine different GST } \\
\text { inhibitor concentrations }\end{array}$ \\
\hline $\begin{array}{c}\text { Plot the non-linear regression } \\
\text { graph to calculate the IC50 }\end{array}$ \\
\hline
\end{tabular}

\begin{tabular}{|l|l|}
\hline CDNB & 1-Chloro-2,4-dinitrobenzene \\
\hline GST & Glutathione S-transferases \\
\hline IC50 & Inhibitory concentration 50 \\
\hline Ki & Constant of inhibition \\
\hline Km & Michaelis-Menten constant \\
\hline
\end{tabular}

5. Ki measurement and mode of inhibition

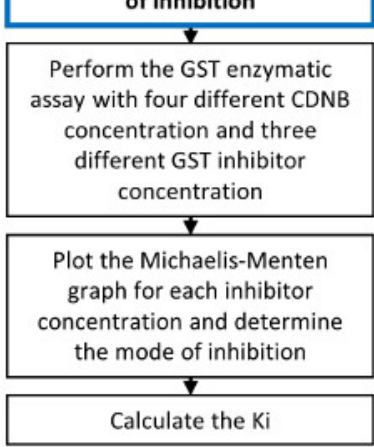

Figure 1: Flowchart describing the steps of the GST enzymatic and inhibition assays. Details about the procedure are presented in the protocol section. Please click here to view a larger version of this figure. 


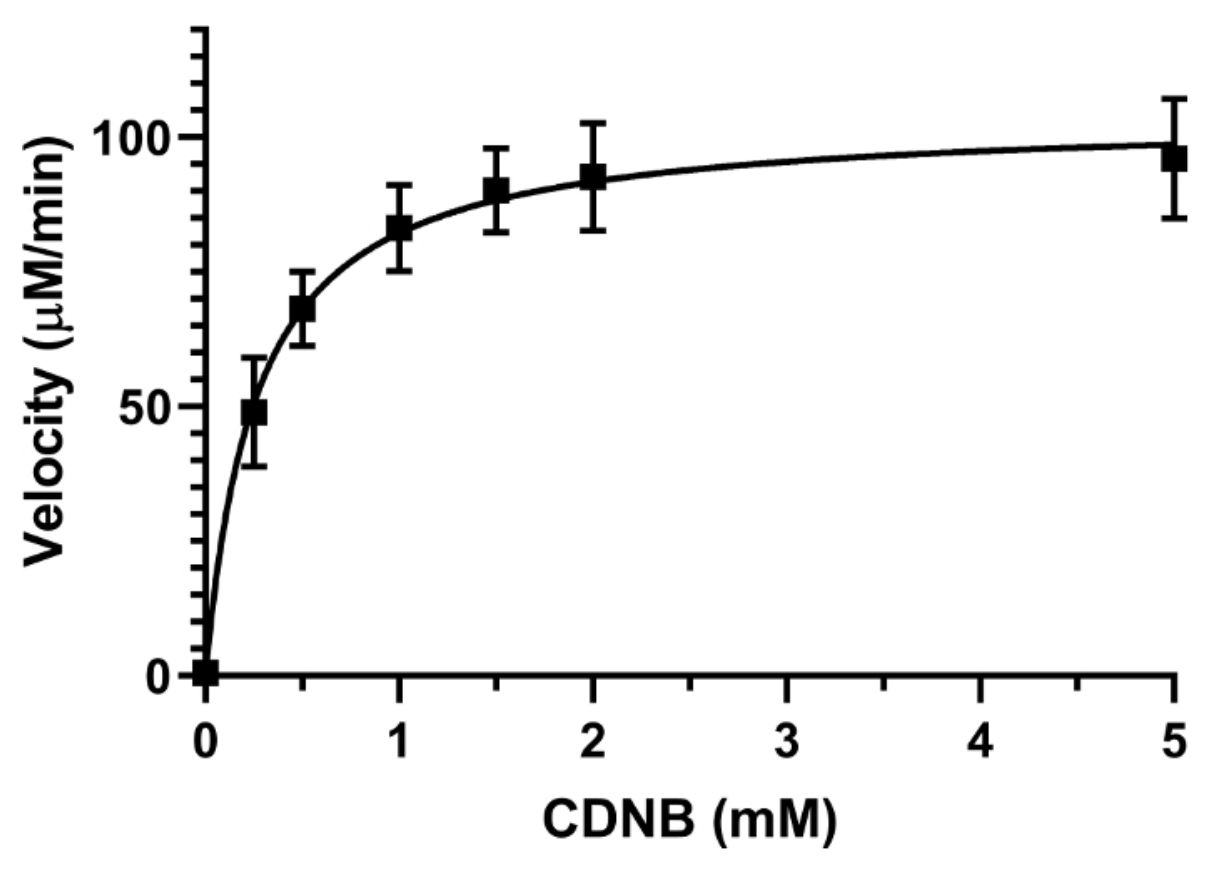

Figure 2: Michaelis-Menten plot of GST enzyme activity. Increased concentration of the substrate CDNB were used with a fixed concentration of GSH $(2.5 \mathrm{mM})$ to determine the GST activity from a pool of GST from equine liver. $\mathrm{K}_{\mathrm{m}}$ value for CDNB was determined as $0.26 \pm 0.08 \mathrm{mM}$ according to the curve of the graph. Each data point on the plot represents the mean of four different experimental runs with SD. Please click here to view a larger version of this figure. 

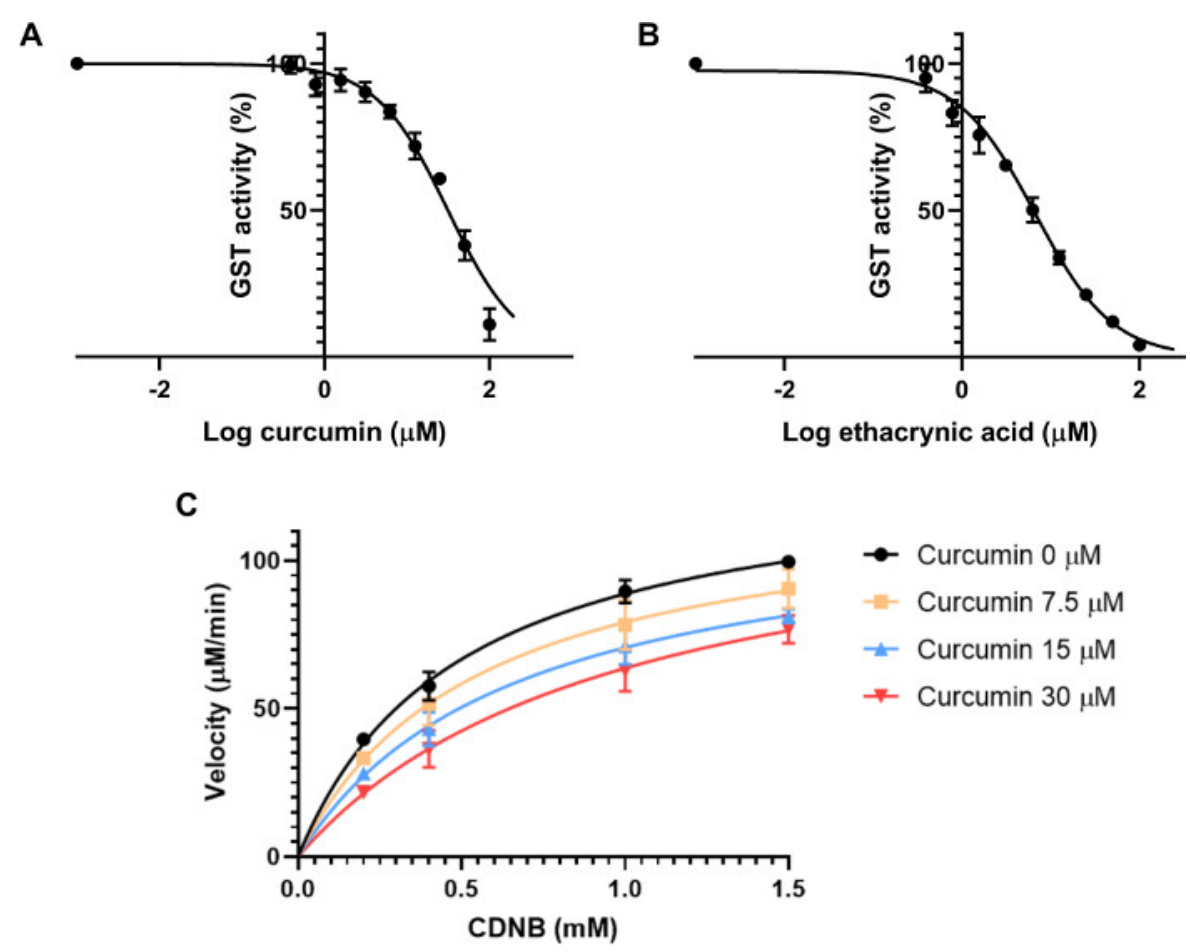

Figure 3: Effect of curcumin and ethacrynic acid on GST enzyme activity. (A-B) Addition of increasing concentrations of either curcumin (A) or the positive control ethacrynic acid (B), whilst keeping the same GST (0.01 U/mL), GSH $(2.5 \mathrm{mM})$ and CDNB $(0.2 \mathrm{mM})$ final concentrations were used to calculate the IC50 of both compounds for GST from equine liver with a non-linear regression. IC50 was determined as $31.6 \pm 3.6 \mu \mathrm{M}$ for curcumin and $6.6 \pm 1.1 \mu \mathrm{M}$ for ethacrynic acid. (C) Michaelis-Menten plot of different concentrations of curcumin, tested against varying concentrations of CDNB substrate indicating a competitive mode of inhibition. With no inhibitor, $V_{\max }$ and $\mathrm{K}_{\mathrm{m}}$ were measured as $132.7 \pm 4.6 \mu \mathrm{M}$ and $0.5 \pm 0.08$ $\mu \mathrm{M}$, respectively. With $30 \mu \mathrm{M}$ of curcumin, $\mathrm{V}_{\max }$ and $\mathrm{K}_{\mathrm{m}}$ were $130.4 \pm 13.1 \mu \mathrm{M}$ and $1.08 \pm 0.39 \mu \mathrm{M}$. Data points in all graphs (A-C) represent the means of three different experimental runs with SD. Please click here to view a larger version of this figure.

\section{Discussion}

We provide a protocol describing each step of a spectrophotometric GST enzyme assay, to screen putative inhibitors (Figure 1, Table 1) and quantify their inhibitory potency. We also emphasized the most crucial criteria to consider for accurate enzyme assays providing reproducible results. Major advantages of the described protocol over other colorimetric methods or mass spectrometry is that this protocol is quick and easy to perform and provide quantitative measurements of the GST activity as well as the inhibition potency of screened molecules.

We present the way of calculating the two most important Michaelis-Menten parameters of an enzyme inhibitor: the IC50 and the $\mathrm{K}_{\mathrm{i}}$. A potent inhibitor will exert the lowest possible $\mathrm{K}_{\mathrm{i}}$ and $\mathrm{IC} 50$, indicating that the affinity between the inhibitor and the enzyme is high ${ }^{30}$. As IC50 is dependent 
upon the enzyme concentration and assay conditions ${ }^{33}$, it may be difficult to use this value to compare inhibitors from different experiments or obtained using other assay conditions $^{34}$. Using the constant of inhibition $\mathrm{K}_{\mathrm{i}}$ is a better indicator of the inhibitory potency of potential compounds. $\mathrm{K}_{i}$ can be used to compare two inhibitors with different modes of inhibition, as it relies solely on the affinity between the inhibitor and the enzyme. However, to have a clear idea of the nature of the inhibition one must determine both of the inhibitor's parameters ${ }^{30}$. We measured curcumins' IC50 and $\mathrm{K}_{\mathrm{i}}$ as $31.6 \pm 3.6 \mu \mathrm{M}$ and $23.2 \pm 3.2 \mu \mathrm{M}$, respectively, indicating that this compound is a potent GST inhibitor. These results confirmed the in silico predictions, that estimated the $\mathrm{K}_{i}$ values between 27.4 to $78.1 \mu \mathrm{M}$ for different human GST isoforms and curcumin.

\section{Enzymatic activity or rate of reaction and amount of enzyme}

As stated above, IC50 is dependent on the enzyme concentration, and conducting an experiment with an unknown level of enzymatic activity might lead to false conclusions $^{33}$. To control for other factors, which might reduce inhibitory activity, one should consider and measure enzymatic activity for each new batch of GSTs. For instance, degradation of an enzymatic batch, caused by too many freeze/thaw cycles, might decrease the activity and thus lead to a lower IC50 even if the experiment was run under the same conditions. In other words, using 0.01 units of enzyme will not give the same results as using 1 unit. Using too many enzymes might lead to a rapid depletion of the substrate and the reaction will not have a linear shape. This parameter could thus lead to inexact result, as no change in absorbance would be seen after a long incubation time.

\section{$\mathrm{K}_{\mathrm{m}}$ Value}

To ensure the best conditions for assessing the type of inhibition exhibited by an inhibitor, the substrate concentration must be equal to or below the Michaelis-Menten constant $\left(\mathrm{K}_{\mathrm{m}}\right) . \mathrm{K}_{\mathrm{m}}$ is represented by the concentration of substrate required to occupy half of the active sites on the enzyme ${ }^{28}$. For instance, higher substrate concentration can counteract a competitive inhibitor and assessing this type of inhibition will be difficult in such setting. Thus, one of the crucial steps in this methodology is the determination of the enzyme's $\mathrm{K}_{\mathrm{m}}$ for the selected substrate (here CDNB). In some studies, this value was not determined and this could lead to false conclusions about the pattern of inhibition caused by the inhibitor, and, if the mode of inhibition is incorrect, the $\mathrm{K}_{\mathrm{i}}$ will be calculated incorrectly as the equation relies on the pattern of inhibition ${ }^{26,28}$. If a different GST isoform is tested, a new assessment of the $\mathrm{Km}$ value is mandatory, as this value is unique for a pair of enzyme and ligand. As we used a concentration of CDNB slightly lower than the $\mathrm{K}_{\mathrm{m}}$ $(0.2 \mathrm{mM})$, that we defined as $0.26 \pm 0.08 \mathrm{mM}$, the predicted competitive mode of inhibition of curcumin on GST was accurately determined.

\section{IC50}

Obtaining a good sigmoidal curve with which to estimate the IC50 requires finding both the bottom and top plateaus. The bottom plateau represents the concentrations of an inhibitor that provide the maximum inhibitory activity. In some cases, a compound might not inhibit the enzyme fully, even at high concentrations, because of such technical issues as solubility. However, tools like GraphPad Prism can fit the bottom plateau quite accurately. The top plateau is made up of concentrations of the inhibitor, which are insufficient to inhibit the enzyme, and therefore the activity is maximal. Both these plateaus are crucial to determining the IC50 as well as concentrations in between, in order to find the slope of the 
curve - then the IC50 can be derived from the shape of the sigmoid curve ${ }^{35}$. Curcumin is poorly soluble in water, thus the maximum concentration used in this assay is limited, to avoid precipitation in the assay solution. Thus, less concentrated solutions, which does not inhibit fully the GST activity, were used. This raised issues for the determination of the bottom plateau. To counter this problem, we predicted bottom values based on the non-linear regression graph, which provided an IC50 of $31.6 \pm 3.6 \mu \mathrm{M}$ for curcumin (Figure $3 \mathrm{~A}$ ). For ethacrynic acid, there was no need to predict the values for the bottom plateau as this compound is soluble in the assay solution and the IC50 was measured at $6.6 \pm 1.1 \mu \mathrm{M}$.

This method can be applied to the most expressed GST isoforms in human, namely GSTA1, GSTM1 or GSTP1. However, this protocol is not suited to quantify the activity of the GSTT1 isoform, as CDNB is not a substrate for this subtype. 36,37 Meanwhile, the protocol can be slightly modified to counter this issue. For instance, using 1,2epoxy-3-(4'-nitrophenoxy)propane (ENPP) as a substrate for GSTT1 and measure the quantity of conjugate at $360 \mathrm{~nm}$ instead of $340 \mathrm{~nm}^{37}$

Steps of protocol can be the adapted and applied to test GST activity and inhibitor testing in cell culture experiments. Measurement of the GST activity on cells treated with and without a GST inhibitor will indicate if this compound can be used in such experimental setting. It is especially interesting when the inhibitor is lipophilic. For instance, we presented that curcumin is a potent GST inhibitor using this protocol. Nevertheless, its application to cellular studies may be limited, as the molecule is poorly soluble in water and degrades quickly in medium. ${ }^{31}$ Another amelioration of this protocol is possible regarding the non-isoform specificity of the substrate CDNB. Using this protocol in cell studies will only give information about the overall GST activity, but not on the activity of precise GST subtype. Adding isoform-specific substrate and/or using specific recombinant GST isoform will permit to test isoform specific GST inhibitors.

To conclude, we describe a complete procedure to test GST inhibitors that have potential to be used in combination with electrophilic chemotherapy. We emphasized the crucial steps of a GST enzyme and inhibition assay, to test potential interesting molecule and determine their efficiency as inhibitor with quantitative values, the IC50 and the $\mathrm{K}_{\mathrm{i}}$. This method can be applied to any putative compound and performed on the most expressed human GST isoforms (GSTA1, GSTM1 and GSTP1), or slightly adapted to perform cell culture studies with GST inhibitors or measure the activity of other interesting GST isoform of choice.

\begin{tabular}{|c|c|c|c|}
\hline Reagents & Name & $\begin{array}{l}\text { Concentration in } \\
\text { the assay solution }\end{array}$ & Other \\
\hline Substrate & CDNB & Measured $\mathrm{K}_{\mathrm{m}}(\mathrm{mM})$ & $\begin{array}{c}\text { Diluted in } 95 \% \text { ethanol. The } \\
\text { final ethanol concentration } \\
\text { should be } \leq 5 \%(\mathrm{v} / \mathrm{v})\end{array}$ \\
\hline \multirow[t]{2}{*}{ Conjugating substrate } & \multirow[t]{2}{*}{ GSH } & \multirow[t]{2}{*}{$2.5 \mathrm{mM}$} & Diluted in water. \\
\hline & & & $\begin{array}{c}\text { The concentration must } \\
\text { saturate the solution. }\end{array}$ \\
\hline
\end{tabular}




\begin{tabular}{|c|c|c|c|}
\hline Buffer & PBS & - & $\mathrm{pH}=7.1$ \\
\hline Enzyme & $\begin{array}{c}\text { Pool of GST isoforms } \\
\text { or pure isoform }\end{array}$ & $\begin{array}{c}0.01 \text { unit } / \mathrm{mL} \text {, determined } \\
\text { experimentally. }\end{array}$ & Diluted in water. \\
\hline \multirow[t]{2}{*}{ GST inhibitor } & \multirow[t]{2}{*}{ Potential compound of choice } & $\begin{array}{l}\text { IC50: } 3 \text { concentrations } \\
\text { that maximally inhibit, } \\
3 \text { that minimally inhibit, } \\
\text { and } 3 \text { in between. }\end{array}$ & \multirow[t]{2}{*}{$\begin{array}{l}\text { Diluted in DMSO and } \\
\text { then in water, to have } \\
\text { a final concentration } \\
\text { of DMSO } \leq 1 \%(\mathrm{v} / \mathrm{v})\end{array}$} \\
\hline & & $\begin{array}{c}\mathrm{K}_{\mathrm{i}}: 3 \text { concentrations } \\
\text { around the IC50. }\end{array}$ & \\
\hline \multicolumn{4}{|c|}{ Parameters } \\
\hline \multicolumn{4}{|c|}{ Room temperature $\left(25^{\circ} \mathrm{C}\right)$} \\
\hline \multicolumn{4}{|c|}{$\mathrm{pH}=7.1$} \\
\hline \multicolumn{4}{|c|}{$\mathrm{DMSO} \leq 1 \%(\mathrm{v} / \mathrm{v})$} \\
\hline \multicolumn{4}{|c|}{ Ethanol $\leq 5 \%(\mathrm{v} / \mathrm{v})$} \\
\hline
\end{tabular}

Table 1: Summary of the reagents and parameters to consider during a GST inhibition assay.

\section{Disclosures}

The authors have nothing to disclose.

\section{Acknowledgments}

This research work was supported by the CANSEARCH Foundation. The authors would like to acknowledge Ms. Laurence Lesne and Mr. Yoann Sarmiento for technical assistance, especially in conducting the replicating experiments while standardizing the assays with inhibitors. Fruitful discussions and inputs by Mr. Denis Marino, Dr. Simona Mlakar and Dr. Vid Mlakar are greatly acknowledged. We thank Dr.Patricia Huezo-Diaz Curtis for her help with the narration of the video. We thank Dr. Muthukumar for his inputs on in silico predictions. We also thank Mr. Darren Hart for his help in English language proof reading of this manuscript.

\section{References}

1. Mannervik, B., Danielson, U.H. Glutathione transferases-structure and catalytic activity. CRC Critical Reviews in Biochemistry. 23 (3), 283-337 (1988).

2. Awasthi, Y.C., Sharma, R., Singhal, S.S. Human glutathione S-transferases. The International Journal of Biochemistry. 26 (3), 295-308 (1994).

3. Rowe, J.D., Nieves, E., Listowsky, I. Subunit diversity and tissue distribution of human glutathione S-transferases: interpretations based on electrospray ionization-MS and peptide sequence-specific antisera. Biochemical Journal. 325 (Pt 2), 481-486 (1997). 
4. Beckett, G.J., Hayes, J.D. Glutathione S-transferases: biomedical applications. Advances in Clinical Chemistry. 30, 281-380 (1993).

5. Oakley, A. Glutathione transferases: a structural perspective. Drug Metabolism Reviews. 43 (2), 138-151 (2011).

6. Townsend, D.M., Tew, K.D. The role of glutathione-Stransferase in anti-cancer drug resistance. Oncogene. 22 (47), 7369-7375 (2003).

7. Tew, K.D. Glutathione-associated Enzymes in Anticancer Drug Resistance. Cancer Research. 54 (16), 4313-4320 (1994).

8. Laborde, E. Glutathione transferases as mediators of signaling pathways involved in cell proliferation and cell death. Cell Death and Differentiation. 17 (9), 1373-1380 (2010).

9. Adler, V. et al. Regulation of JNK signaling by GSTp. The EMBO Journal. 18 (5), 1321-1334 (1999).

10. Cho, S.G. et al. Glutathione S-Transferase Mu Modulates the Stress-activated Signals by Suppressing Apoptosis Signal-regulating Kinase 1. Journal of Biological Chemistry. 276 (16), 12749-12755 (2001).

11. Hayes, J.D., Flanagan, J.U., Jowsey, I.R. Glutathione Transferases. Annual Review of Pharmacology and Toxicology. 45 (1), 51-88 (2005).

12. Lo, H.W., Ali-Osman, F. Genetic polymorphism and function of glutathione S-transferases in tumor drug resistance. Current Opinion in Pharmacology. 7 (4), 367-374 (2007).

13. Ansari, M. et al. Glutathione S-transferase gene variations influence BU pharmacokinetics and outcome of hematopoietic SCT in pediatric patients. Bone Marrow Transplantation. 48 (7), 939-946 (2013).

14. Mahajan, S., Atkins, W.M. The chemistry and biology of inhibitors and pro-drugs targeted to glutathione Stransferases. Cellular and molecular life sciences: CMLS. 62 (11), 1221-1233 (2005).

15. Allocati, N., Masulli, M., Ilio, C.D., Federici, L. Glutathione transferases: substrates, inihibitors and pro-drugs in cancer and neurodegenerative diseases. Oncogenesis. 7 (1), 8 (2018).

16. Aggarwal, B.B., Kumar, A., Bharti, A.C. Anticancer potential of curcumin: preclinical and clinical studies. Anticancer Research. 23 (1A), 363-398 (2003).

17. Han, S.S., Chung, S.T., Robertson, D.A., Ranjan, D., Bondada, S. Curcumin causes the growth arrest and apoptosis of B cell lymphoma by downregulation of egr-1, c-myc, bcl-XL, NF-kappa B, and p53. Clinical Immunology (Orlando, Fla.). 93 (2), 152-161 (1999).

18. Golonko, A., Lewandowska, H., Świsłocka, R., Jasińska, U.T., Priebe, W., Lewandowski, W. Curcumin as tyrosine kinase inhibitor in cancer treatment. European Journal of Medicinal Chemistry. 181, 111512 (2019).

19. Awasthi, S. et al. Curcumin-glutathione interactions and the role of human glutathione S-transferase P1-1. Chemico-Biological Interactions. 128 (1), 19-38 (2000).

20. Appiah-Opong, R., Commandeur, J.N.M., Istyastono, E., Bogaards, J.J., Vermeulen, N.P.E. Inhibition of human glutathione S-transferases by curcumin and analogues. Xenobiotica; the Fate of Foreign Compounds in Biological Systems. 39 (4), 302-311 (2009).

21. Dubey, V., Owusu-Apenten, R. Curcumin Restores Glutathione-S-Transferase Activity for LNCaP Prostate 
Cancer Cells. Pure and Applied Chemistry. 2, 61-72 (2014).

22. Habig, W.H., Pabst, M.J., Jakoby, W.B. Glutathione Stransferases. The first enzymatic step in mercapturic acid formation. The Journal of Biological Chemistry. 249 (22), 7130-7139 (1974)

23. Johnson, K.A., Goody, R.S. The Original Michaelis Constant: Translation of the 1913 Michaelis-Menten Paper. Biochemistry. 50 (39), 8264-8269 (2011).

24. Ochs, R.S. Understanding Enzyme Inhibition. Journal of Chemical Education. 77 (11), 1453 (2000).

25. Bisswanger, H. Enzyme assays. Perspectives in Science. 1 (1), 41-55 (2014).

26. Acker, M.G., Auld, D.S. Considerations for the design and reporting of enzyme assays in high-throughput screening applications. Perspectives in Science. 1 (1), 56-73 (2014).

27. Cheng, A.L. et al. Anticancer Research. 21 (4B), 2895-2900 (2001).

28. Yang, J., Copeland, R.A., Lai, Z. Defining Balanced Conditions for Inhibitor Screening Assays That Target Bisubstrate Enzymes. Journal of Biomolecular Screening. 14 (2), 111-120 (2009).

29. Uppugunduri, C. R. S., Muthukumaran, J., SantosSilva, T., Ansari, M. Identification of putative substrates and inhibitors for Glutathione S-transferases using computational methods. Zenodo. (2017).

30. Burlingham, B.T., Widlanski, T.S. An Intuitive Look at the Relationship of Ki and IC50: A More General Use for the Dixon Plot. Journal of Chemical Education. 80 (2), 214 (2003).

31. Wang, Y.J. et al. Stability of curcumin in buffer solutions and characterization of its degradation products. Journal of Pharmaceutical and Biomedical Analysis. 15 (12), 1867-1876 (1997).

32. Copeland, R.A. Evaluation of enzyme inhibitors in drug discovery. A guide for medicinal chemists and pharmacologists. Methods of Biochemical Analysis. 46, $1-265$ (2005).

33. Kalliokoski, T., Kramer, C., Vulpetti, A., Gedeck, P. Comparability of Mixed IC50 Data - A Statistical Analysis. PLOS ONE. 8 (4) (2013).

34. Brandt, R.B., Laux, J.E., Yates, S.W. Calculation of inhibitor $\mathrm{Ki}$ and inhibitor type from the concentration of inhibitor for $50 \%$ inhibition for Michaelis-Menten enzymes. Biochemical Medicine and Metabolic Biology. 37 (3), 344-349 (1987).

35. Brooks, H.B. et al. Basics of Enzymatic Assays for HTS. at <https://www.ncbi.nlm.nih.gov/books/NBK92007/>. Eli Lilly \& Company and the National Center for Advancing Translational Sciences. (2012).

36. Arakawa, S. et al. Evaluation of hepatic glutathione transferase Mu 1 and Theta 1 activities in humans and mice using genotype information. Drug Metabolism and Disposition: The Biological Fate of Chemicals. 40 (3), 497-503 (2012).

37. Sherratt, P.J., Pulford, D.J., Harrison, D.J., Green, T., Hayes, J.D. Evidence that human class Theta glutathione S-transferase T1-1 can catalyse the activation of dichloromethane, a liver and lung carcinogen in the mouse. Comparison of the tissue distribution of GST T1-1 with that of classes Alpha, Mu and Pi GST in human. The Biochemical Journal. 326 (3), 837-846 (1997). 